\title{
La representación política de las mujeres en México
}

\author{
Flavia Freidenberg (Ed.)
}

Ciudad de México: IIJ-UNAM e INE. 2018. 300 páginas.

\section{Karolina M. Gilas}

DOI: https://doi.org/10.46468/rsaap.14.1.R3

El estudio de la representación política de las mujeres es uno de los grandes temas que, en las últimas décadas, ha transformado la ciencia política y nuestro entendimiento de los fenómenos representativos. Cuando quedó evidenciado que el reconocimiento de los derechos políticos y de la igualdad jurídica entre los hombres y las mujeres no se tradujo en la inclusión plena de la mitad de la población en la vida pública y en el ejercicio del poder político, el estudio de los factores que determinan los alcances de esa participación se ha convertido en un importante campo de investigación (Waylen et al., 2013). Entre estos estudios son particularmente importantes aquellos que, desde diversos ámbitos del neoinstitucionalismo, la política comparada y los estudios subnacionales, aportaron evidencias empíricas para identificar los obstáculos para la representación política de las mujeres y los mecanismos que permitieron su avance (Waylen et al., 2013; Lovenduski, 1998).

En esta línea se ubica el libro editado por Flavia Freidenberg, dedicado al estudio de la representación política de las mujeres en México. Detrás de esta publicación se encuentra un enorme esfuerzo de sistematización de los datos sobre quienes han ocupado escaños en el Congreso federal y en los congresos de las entidades federativas entre 1990 y 2016. Estos datos, recopilados en el marco del proyecto \# MujeresPolíticas, inaccesibles en ninguna otra fuente, ofrecen un panorama amplio, profundo y detallado sobre el largo y sinuoso camino que fue para las mujeres romper los techos y eliminar las barreras que les impedían acceder a los espacios de representación en México.

A partir de los datos generados, las investigadoras e investigadores del proyecto —Ninfa Hernández, Georgina Flores-Ivich, Valeria Ordoñez, María Cristina Osornio, Raymundo Alva Huitrón, Rodrigo Salazar Elena y la propia Freidenberg - realizaron análisis de los factores que, en los diversos contextos de la política mexicana nacional y subnacional, facilitan o dificultan el acceso de las mujeres a la representación descriptiva.

La aplicación del Índice de Fortaleza del Diseño Electoral de Género (IFDEG) para las 32 entidades federativas y para el Congreso federal, realizada por Freidenberg y Alva Huitrón, les permite concluir acerca de la importancia del diseño de las cuotas de género. Su hallazgo principal es que la homologación de la regulación de la paridad, con la cual las normas federales permearon al ámbito estatal, ha permitido fortalecer las condiciones favorables para la representación femenina. Al mismo tiempo, su trabajo apunta a que aún persisten importantes obstáculos para la participación política de las mujeres, en particular el uso frecuente de estrategias que pretenden evitar el cumplimiento 
de las cuotas por parte de los partidos políticos.

Hernández Trejo, quien evalúa la representación descriptiva de las mujeres en los congresos estatales, evidencia las diferencias en la implementación de las cuotas y de la paridad entre las entidades federativas. Su trabajo apunta a que, más allá de las cuotas y su efectividad, la representación política depende en gran medida de los aspectos no formales, como la voluntad de los partidos y la cultura política dominante.

En su capítulo, Flores-Ivich y Freidenberg exploran los factores detrás de las diferencias entre los niveles de representación descriptiva femenina en los congresos de las entidades federativas. Su trabajo muestra el impacto determinante de la fortaleza del diseño de las cuotas para el éxito electoral de las mujeres, aunque también esbozan conclusiones tentativas sobre el impacto de las características personales de las candidatas y del papel de las autoridades electorales.

Por su parte, Ordoñez Ghio y Flores-Ivich analizan los resultados de la implementación de una regla novedosa, aprobada en México con la reforma de 2014, que prohíbe a los partidos políticos postular las candidaturas de un solo género en aquellos distritos en los que hubiese obtenido los porcentajes de votación más baja (los llamados "distritos perdedores"). Los datos empíricos evidencian que la medida es compleja en su implementación y que, en ciertas condiciones, resulta poco efectiva para evitar la tendencia partidista de postular a las mujeres en posiciones o distritos con pocas posibilidades de victoria.

El capítulo de Freidenberg estudia la manera en la que los partidos políticos han reaccionado a la nueva dinámi- ca política y en qué medida estos promueven y obstaculizan la igualdad de género al interior de sus organizaciones y en el acceso al poder. Para ello, propone una herramienta para la evaluación de la igualdad sustantiva al interior de los partidos. Sus hallazgos apuntan a la persistencia de numerosos obstáculos relacionados con los procesos internos, con la distribución de los recursos, con un bajo compromiso por la igualdad y con frecuentes casos de violencia contra las mujeres.

Salazar Elena y Osornio Guerrero analizan la complejidad generada por la conjugación de tres normas aparentemente contradictorias: la obligación de la postulación paritaria, la democracia interna y la posibilidad de reelección. Su trabajo propone evitar las tensiones transitando hacia un modelo de escaños reservados o de listas cerradas.

Alva Huitrón amplía el análisis de los obstáculos existentes al acceso de las mujeres a los cargos legislativos desde la perspectiva de los recursos de campaña de los que disponen. Su capítulo demuestra que los partidos no impulsan una estrategia a favor de fortalecimiento del liderazgo femenino, y apunta a que sería necesario construir condiciones de igualdad económica entre las campañas de las candidaturas femeninas y masculinas.

Finalmente, Freidenberg y Osornio Guerrero cierran el volumen apuntando a la violencia política en razón de género como una consecuencia no prevista y no deseada del incremento del número de las mujeres en los cargos legislativos.

La Representación Política de las Mujeres en México es un libro fundamental para comprender la ruta mexicana hacia la paridad de género y el largo y sinuoso camino que permitió construir 
las condiciones adecuadas para promover el acceso de las mujeres a los cargos legislativos. Es una crónica detallada de la evolución y de las condiciones actuales de la participación política de las mujeres mexicanas y, al mismo tiempo, un extraordinario análisis que da cuenta de los obstáculos culturales, partidistas, político-institucionales y estructurales que obstaculizan, aún hoy, el desarrollo de las actividades políticas por parte de las mujeres. Estos obstáculos suponen, al mismo tiempo, dos agendas. La primera es una agenda de investigación futura, necesaria para estudiar la evolución de estas trabas y la efectividad de las medidas implementadas para su eliminación. La segunda es una agenda de políticas públicas que se requieren para que estos obstáculos se conviertan en una cosa del pasado y para que nada vuelva a impedir la plena participación de las mujeres en la política.

\section{Referencias bibliográficas}

Lovenduski, J. (1998). Gendering research in political science. En $A n$ nual Review of Political Science, 1: 333-35.

Waylen, G., K. Celis,J. Kantola, y L. S. Weldon(Eds.) (2013). The Oxford Handbook of Gender and Politics. Oxford: Oxford University Press. 